\title{
The Cultivation of Cross-cultural Communication Ability for Students of the High Vocational Tourism College in Sino-foreign Education Cooperation
}

\author{
Danlu LIAO \\ The Department of International Tourism, \\ Chongqing Vocational Institute of Tourism
}

\begin{abstract}
In recent years, with rapid development of Sino-foreign cooperation in higher vocational colleges, it puts forward higher requirements for students' English comprehensive ability. According to the characteristics of higher vocational colleges of tourism, as well as the author's own teaching experience, this paper elaborates the characteristics of English teaching in the Sino-foreign cooperative education, and the ways to cultivate and improve cross-cultural communication ability for students in tourism colleges.
\end{abstract}

Keywords: Sino-foreign Education Cooperation; Tourism College; Cross-cultural Ability

\section{Introduction}

In recent years, the strategy of internationalization of education has been promoted in China along with China's opening-up to the outside world and economic development, and simultaneously the international exchanges and cooperation in the field of education are continuously extended, and any higher vocational colleges try this model to achieve new development and breakthrough. Since China's accession to WTO, China's tourism gradually develops toward the international market and steps into the international competition pattern of tourism and the service personnel good at foreign languages are demanded increasingly. The Basic Requirements for English Course Teaching in Higher Vocational Education, issued by the Ministry of
Education in 2000, clearly showed the guideline of "top priority is given to practical use", and the practical English teaching system targeted at social demand and directed by employment, aiming to train the ability of students in English application. Therefore, an understanding of Chinese customs and semantics must be enhanced among students in English teaching, so as to strengthen students' sensitivity to culture, understand cultural differences, and improve students' intercultural communication ability. Combined with the characteristics of Chongqing Vocational Institute of Tourism, how to train the cross-cultural communication ability for students in tourism colleges under the background of globalization and Sino-foreign cooperative education is discussed in this paper.

\section{The situation of higher vocational colleges in Sino-foreign cooperative education}

In recent years, the international exchanges and cooperation in the field of education are constantly expanded along with the continuous development of the national economy and the deepened change of higher education, and Sino-foreign cooperative education has become an important form of Chinese institutions of higher learning to carry out external exchange, cooperation and personnel training. Combined with the current situation of the tourism education in higher vocational colleges and also the objective of application-oriented personnel training, the training of students' cross-cultural communication ability is necessarily emphasized, in order to promote the comprehensive ability of 
tourism college students in English application. However, it is found that the cultivation of intercultural communication ability is not really reflected in the traditional international cooperative education model.

First, teaching contents are cooperative. In the curriculum provision of Sino-foreign cooperative education, quite a number of courses are offered by cooperative foreign colleges, and accordingly original teaching materials are provided by foreign colleges, and the teaching is finished by Chinese teachers and the learning results of students are evaluated according to the evaluation model of foreign colleges. All these put forward higher requirements for the ability of the practical English ability of students in higher vocational colleges.

Second, faculty and teaching methods are cooperative. Teachers in Chinese colleges usually graduated from English programs and do not have a foreign educational background, and thus, the effectiveness of the cultural input from English-speaking countries is not very ideal in the classroom teaching; the Chinese teacher's imitating ideas and cramming teaching model are not conducive to the training of students' language application ability. Moreover, requirements are raised in the cooperative education for the TOEFL and IELTS scores. Therefore, in the process of Chinese teaching, examination-oriented instruction, technique introduction, and past test paper exercises are necessarily stressed.

3. Strategies of training the cross-cultural communication ability for the students of tourism colleges in Sino-foreign cooperative education

\subsection{Clearly recognizing the international cooperative education trend for higher vocational colleges and developing tourism characteristics}

At present, the main way of Sino-foreign cooperative education is "education import".
That is to say, teaching resources, contents and ideas can be introduced by Chinese colleges, while the huge student sources market of China is focused by foreign colleges and their direct motives are economic benefits (Guanghuang YE, 2005).

Chongqing Vocational Institute of Tourism is taken for example - it is located in the southeast of Chongqing areas where many minorities live and tourism resources are abundant. In the "Twelfth Five-Year" Plan of Chongqing Municipal Government, the goal of constructing tourism to be a strategic pillar industry for improving people's living standards and promoting the city's sound and rapid economic development, constructing Chongqing into a world famous tourist destination and the sightseeing place of China's western region, and constructing "the Folk-custom Eco-tourism Zone of Southeast Chongqing" is explicitly raised so that it becomes an important growth pole of Chongqing tourism. As a result, a good foundation and environment is provided by policy support for Chongqing Vocational Institute of Tourism to develop foreign cooperation in tourism, and simultaneously the self-value can increase in cooperative negotiations and thus more colleges and experts will be invited and more choices are available.

\subsection{Constructing a higher vocational English teaching model with tourism characteristics}

\subsubsection{Choosing teaching materials and teaching methods}

Teaching materials must be chosen based on the characteristics of tourism colleges and the students' actual conditions, in which the teaching ideas and model of higher vocational colleges to train application-oriented personnel are necessarily reflected. At the same time, the choice must be helpful for Chinese teachers to instruct students according to the actual aptitude and independently adjust the difficulty of the teaching material in the scope of syllabus and 
based on the students' situation and learning progress.

From the perspective of teaching method, the ability of higher vocational college students in language application and cross-cultural communication must be emphatically trained and developed. Students can be required to read a lot of English articles in extra-curricular time and tasks such as research, inductive analysis and conclusion and investigation report can be assigned for students to finish.

\subsubsection{Faculty and teachers' role}

In the teaching process, the teaching quality and effect are directly affected by the quality of faculty. Therefore, the training of local outstanding young teachers and key teachers must be enlarged, and related teachers are arranged to receive training and academic exchanges in foreign countries, aiming to learn the cooperative parties' teaching ideas and methods and then improve the local teachers' scientific research ability and level. First, through a variety of forms such as site view and emulation, group discussion and literature reading, the language literacy of local teachers can be improved, and then they can apply what they have learned to the practice of cross-cultural communication, for the purpose of promoting the teaching based on researches. Second, great importance should be attached to recruiting and selecting foreign teachers. Foreign schools can be required to dispatch full-time teachers who are rich in teaching experience and have a certain understanding of Chinese culture. In addition to the routine teaching, foreign teachers are allowed to participate in the teaching process supervision and guide the teaching work. Finally, the communication between local teachers and foreign teachers can be strengthened; teaching and research cooperation ways can be applied to jointly compile the teaching materials with local characteristics and fitting tourism colleges, so as to research the higher vocational teaching methods together. The ways such as mutually listening to course teaching and preparing lessons together can be taken, so as to grasp the key and difficult teaching points, unify the teaching contents, integrate the tourism characteristics, and commonly improve the teaching quality.

Teachers should play a role of facilitator and guide in the teaching process. The teaching process should be always student-centered, and students can be actively guided by teachers to actively think and practice. In class, themes can be set-group discussion, presentation in English, English interpretation on tourist destinations, and simulated English guide can be used. After class, English corner, English speech contest, English drama competition, and English tour guide contest can be often implemented among students, so as to stimulate students' interest and motivation in learning English by combining with professional tourism knowledge.

\subsubsection{Building a hierarchical, grouping teaching} model for classes

In Sino-foreign cooperative education, how to ensure students' English reach the teaching objective is a very critical question because students' English foundation is different greatly. Students need to take part in TOEFL and IELTS, and their scores in these tests directly affect whether they can complete the learning of major courses and smoothly graduate from school. Therefore, hierarchical, grouping teaching can be implemented according to different English foundations of students. By written and oral English tests, students can be grouped and different learning contents and learning tasks can be arranged. At the same time, different teaching methods must be taken in light of different language ability of students. For example, the command of basic vocabularies and sentence patterns can be enhanced through listening and repeating, reading loudly and clearly, dialogue, and reciting, among the students whose English foundation is weak; students' thinking can be expanded through topic setting, investigation, interviewing, and reporting, among the students whose English foundation is good, aiming to 
expand students' thinking and cultivate their ability in independent learning. In view of the students' English learning conditions, listening, speaking, reading, writing and translation as five English skills should be always maintained no matter they choose to study oversea or domestically. The emphasis of different levels of students on language and skills is different, but the ultimate goal is to help students reach English proficiency and cross-intercultural communication ability demanded by major learning and future work.

3.2.4 Establishing a system for evaluating the learning effect

In Sino-foreign cooperative education, the evaluation on the major courses of students usually gives top priority to written examination; learning performance at ordinary times and final test results are comprehensively calculated to a scale; learning performance at ordinary times is based on after-class exercises and attendance rate. In the evaluation on students' English learning achievements, the proportion of evaluating learning performance must be higher; tests and evaluations centered at the improvement of the cross-cultural communication ability can be set up; students' usual performance and actual ability to solve the problems must be emphasized. Therefore, different modules and evaluation means can be adopted, and oral English teaching can be purposefully introduced to the classroom. For example, tasks such as assigning queries, reading related English information, and writing abstracts can be arranged for students before class, to evaluate students' ability in English reading and writing; English presentation, discussion, summary and induction are used by students in class, to evaluate students' ability in English listening and speaking; topics are set after class, and students are differently grouped and required to make researches in a targeted way, to generate an English report and accordingly evaluate students' comprehensive ability in English application. At the same time, the real cross-cultural communication scenes can be set up by combining with the special characteristics of tourism colleges to make evaluations.

\section{Conclusion}

Sino-foreign cooperative education is an inevitable trend of higher vocational education development in China, and students' ability in cross-cultural communication is necessarily trained in English teaching. Teachers, in tourism colleges, must be aware of the fact that tourism is a kind of cross-cultural communication and the cultural integration is very important in English teaching, and also actively mobilize the enthusiasm of students for learning foreign culture. When the professional and cultural knowledge is continuously improved, students are helped to adapt to Sino-foreign cooperative educational projects, training students' correct understanding and attitude toward cultural differences and ability in processing cultural differences, so that the communication barriers caused by cultural differences are overcome, the students' cross-cultural communication ability is trained, and ultimately the goal of cultivating international tourism talents comes true.

\section{Acknowledgement}

This paper aided financially by the "Twelfth Five-year" Education Science Plan Project of Chongqing, "the Integration of the National Culture into English Teaching for Students in High Vocational Education of Tourism" (No.2012-GX-215).

\section{References}

[1] Kramsch, Claire. Context and Culture in Language Teaching [M]. Shanghai: Shanghai Foreign Language Education Press, 1999.

[2] Hong-bo DENG. The Cultivation of English Application Ability in Chinese-Foreign Cooperation Projects [J]. Journal of Teaching and Professional, 2007, (561). 
[3] Gui-ping LIU. English Language Education in Higher Education based on Chinese-Foreign Cooperation [J]. Journal of Chengdu University, 2007, (11).

[4] Wenzhong HU. The Communication between Different Cultures and the English Teaching [J]. Journal of English Teaching and Research, 1985, (4).
[5] Hexiang LUO. Study on the Effect of Culture Teaching in Training the Cross-cultural Communication Competence of the Students in Higher Vocational Colleges [J]. Journal of Jiangxi School of Administration, 2008,

(2). 